\title{
Chiral Discrimination of D- and L-Amino Acids Using Iodinated Tyrosines as Chiral References: Effect of Iodine Substituent
}

\author{
Sangeeta Kumari, ${ }^{a}$ Sripadi Prabhakar, ${ }^{a}$ Mariappanadar Vairamani, ${ }^{\text {a }}$ \\ Chebrolu Lavanya Devi, ${ }^{\text {b }}$ Gunturu Krishna Chaitanya, \\ and Kotamarthi Bhanuprakash ${ }^{\mathrm{b}}$ \\ ${ }^{a}$ National Center for Mass Spectrometry, Indian Institute of Chemical Technology, Hyderabad, India \\ ${ }^{\mathrm{b}}$ Inorganic Chemistry Division, Indian Institute of Chemical Technology, Hyderabad, India
}

L-Tyrosine and iodinated L-tyrosines, i.e., 3-iodo-L-tyrosine and 3,5-diiodo-L-tyrosine, are successfully used as chiral references for the chiral discrimination of aliphatic, acidic, and aromatic amino acids. Chiral discrimination is achieved by investigating the collision-induced dissociation spectra of the trimeric complex $\left[\mathrm{Cu}^{\mathrm{II}}(\mathrm{ref})_{2}(\mathrm{~A})-\mathrm{H}\right]^{+}$ion generated by electro spraying the mixture of D- or L-analyte amino acid (A), chiral reference ligand (ref) and $\mathrm{M}^{\mathrm{II}} \mathrm{Cl}_{2}$ $(\mathrm{M}=\mathrm{Ni}$ and $\mathrm{Cu})$. The relative abundances of fragment ions resulted by the competitive loss of reference and analyte amino acids are considered for measuring the degree of chiral discrimination by applying the kinetic method. The chiral discrimination ability increases as the number of iodine atom increases on the aromatic ring of the reference and the discrimination is better with $\mathrm{Cu}$ when compared with $\mathrm{Ni}$. A large chiral discrimination is obtained for aliphatic and aromatic amino acids using iodinated L-tyrosine as the reference. Computational studies on the different stabilities of the diastereomeric complexes also support the observed differences measured by the kinetic method. The suitability of the method in the measurement of enantiomeric excess over the range of $2 \%$ to $100 \%$ ee with relative error $0.28 \%$ to $1.6 \%$ is also demonstrated. (J Am Soc Mass Spectrom 2007, 18, 1516-1524) ( 2007 American Society for Mass Spectrometry

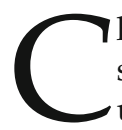
hirality is a characteristic feature of biological systems. A number of approaches have been used for studying the chiral recognition of organic compounds in the solution phase, which include circular dichroism [1], capillary electrophoresis [2], nuclear magnetic resonance [3], use of chiral reagents in chromatography $[4,5]$, etc. Although mass spectrometry was originally thought of as a chirally blind technique, it is now accepted as a powerful analytical tool for differentiating enantiomeric compounds through their interactions with chiral reference molecules. The mass spectrometry based chiral recognition (gas phase) methods fall into the following categories: (1) measurement of relative abundance of diastereomeric adducts ions formed between analyte of interest and a chiral reference [6-9]; (2) Host-guest ion/molecule (equilibrium) reactions; diastereomeric complex ion allowed to react with a neutral reagent (guest) either chiral or non chiral. Chiral discrimination is achieved by investigating the differences in exchange rate with time due to chirality of the analyte [10-16]; (3) Collision induced dissociation mass spectra of proton or metal bound

Address reprint requests to Dr. M. Vairamani, National Center for Mass Spectrometry, Indian Institute of Chemical Technology, Uppal Road, Tarnaka, Hyderabad 500 007, India. E-mail: vairamani@iict.res.in diastereomeric adduct ion formed between an analyte and a chiral reference shows the difference in fragmentation pattern [17-22].

The kinetic method has been used for the estimation of thermodynamic properties as well as for chiral discrimination [21-34]. In this method, mostly the cluster ion $\left[\mathrm{M}^{\mathrm{II}}(\mathrm{ref})_{2} \mathrm{~A}-\mathrm{H}\right]^{+}$consisting of an analyte molecule of interest (A), two molecules of chiral reference ligand (ref), and a metal ion arranged in either octahedral or tetrahedral fashion around the metal ion are generated in the source of a mass spectrometer and their dissociation studied (Scheme 1). Chiral discrimination of two enantiomers can be achieved by measuring the abundance ratio of two fragment ions (kinetic method) [23-33], or abundance ratio of one fragment ion to that of precursor ion (chiral ratio method) [17-19]. Mostly transition-metal bound cluster ions are preferably used over other metal bound cluster ions because they give rise to large chiral recognition due to enhanced contribution to stereochemical effects from d-electronic orbitals of transition metals [25, 26]. However, it is not necessary to use transition-metal bound cluster ions for chiral recognition because there are some reports in the literature of using other metal ions such as Ca [17].

Abundance ratio of two fragment ions is measured for the two enantiomers represented by $R_{D}$ or $R_{L}$. Ratio 


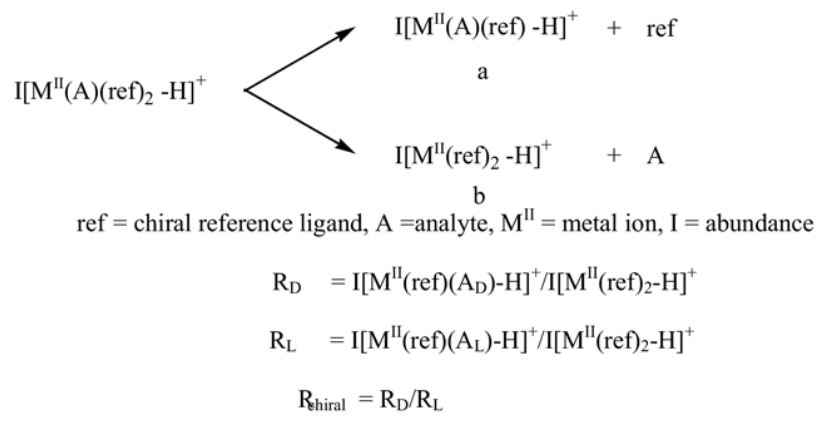

Scheme 1

of $R_{D}$ and $R_{L}$ is further represented by $R_{\text {chiral }}$, which shows the degree of discrimination. The best systems are those that provide value for $R_{\text {chiral }}$ far from unity, provided accurate measurement of abundance ratio is possible, which in turn depends on the difference in metal ion affinities between reference and analyte. If the difference in the metal ion affinity between reference and analyte is too large, the dissociation of trimeric cluster predominantly favors only one fragmentation channel, and this prevents accurate measurement of the abundance of other fragment ion. The kinetic method has been successfully used for the chiral discrimination of amino acids [20, 21], $\alpha$ - hydroxy acids [23-25], chiral drugs [29-32], sugars [26], and chiral and isomeric dipeptides [27, 28]. N-blocked amino acids have been extensively used as reference for a wide range of analytes [24-27]. However, limited selectivity and application range of the chiral selectors are still major problems that can be addressed in chiral analysis.

Cooks et al. [20] studied the chiral discrimination of all the natural amino acids using the kinetic method by choosing amino acids themselves as reference and copper as a central metal ion. They successfully discriminated naturally occurring amino acids using phenylalanine and other amino acids as reference. They concluded that the amino acids with an aromatic sidechain are good choices as references, and suggested that this could be due to $\pi$ - $\pi$ stacking interactions between the aromatic side-chain in the reference and the carboxylate group in the analyte. Similar results were obtained when the same method was applied using $\mathrm{Ni}$ as the central metal ion, however, the selectivity was found to be less with $\mathrm{Ni}$ when compared with $\mathrm{Cu}$. L-Tyrosine, despite of its aromatic nature, was not used as a reference in combination with $\mathrm{Cu}$; but with $\mathrm{Ni}$ it was used as a reference and reported to give poor selectivity [21]. The authors concluded that the hydroxyl group in the side-chain of the analyte/reference shows negative effect on chiral selectivity. Cooks et al. [25] have also studied effect of hydroxyl substituents on L-Phe towards the chiral discrimination of $\alpha$-hydroxy acids. L-Tyr (4-hyroxy L-Phenylalanine) showed chiral selectivity similar to that of L-Phe whereas, a significant increase in chiral selectivity was achieved when two hydroxy groups were present on the aromatic ring of
L-Phe (L-DOPA). Thus the chiral differentiation is highly dependent on the choice of the chiral reference compound and the central metal ion.

The effects of iodine substituent on the stability of $\mathrm{Cu}$ (II) complexes have not been tested in the gas phase towards the chiral discrimination. In that sense we thought selection of L-tyrosine, 3-iodo-L-tyrosine, and 3,5-diiodo-L-tyrosine will provide some control over the chiral discrimination, especially in the case of naturally occurring amino acids. Also iodinated Ltyrosines, 3,5,3'-triiodo-L-thyronine (T3) and Lthyroxine (T4) are known to involve in the control of tissue development and differentiation, the regulation of oxygen consumption, and the promotion of various metabolic processes [35]. ${ }^{\circ}$ Iodo ${ }^{\circ}$ groups ${ }^{\circ}$ of $^{\circ}$ the ${ }^{\circ}$ hormones are particularly intriguing because they are essential for the hormone activity, and owing to their bulkiness and polarizability, the iodo groups should have an important role in the hormone receptor binding through noncovalent interactions. Herein, we report the use of L-tyrosine and iodinated L-tyrosines as a reference in combination with $\mathrm{Cu}$ and $\mathrm{Ni}$, and the effect of iodine substituent in chiral discrimination of amino acids using the kinetic method.

\section{Experimental}

\section{Materials}

All the D- and L-amino acids, and 3,5-diiodo-L-tyrosine were purchased from Aldrich (Steinheim, Germany), and 3-iodo-L-tyrosine was purchased from Fluka (Buchs, Switzerland). Methanol (HPLC grade) was obtained from Merck (Mumbai, India). Stock solutions $(1 \mathrm{mM})$ of 3-iodo-L-tyrosine, 3,5-diiodo-L-tyrosine and amino acids (in 50:50 vol/vol water/methanol), and copper chloride (in Milli Q water Billerica, MA) were prepared. These stock solutions are mixed in appropriate volumes and diluted with 50:50 water/methanol (vol/vol) to obtain a final concentration of $50: 50 \mu \mathrm{M}$ (1:1) of reference (3-iodo-L-tyrosine or 3,5-diiodo-Ltyrosine) and amino acid in the presence of $12.5 \mu \mathrm{M}$ $\mathrm{NiCl}_{2} / \mathrm{CuCl}_{2}$.

\section{Mass Spectrometry}

The experiments were performed using a LCQ ion trap mass spectrometer (Thermo Fisher, San Jose, CA), equipped with an ESI source. The data acquisition was under the control of Xcalibur software. The typical source conditions were: spray voltage, $4.5 \mathrm{kV}$; capillary voltage, $3 \mathrm{~V}$; heated capillary temperature, $200^{\circ} \mathrm{C}$; tube lens offset voltage, $10 \mathrm{~V}$; sheath gas $\left(\mathrm{N}_{2}\right)$ flow rate, 20 units; and helium was used as damping gas. For the ion trap mass analyzer, the automatic gain control (AGC) settings were $2 \times 10^{7}$ counts for full-scan mass spectrum and product ion mass spectrum with a maximum ion injection time of $200 \mathrm{~ms}$. In the full-scan $\mathrm{MS}^{2}$ mode, the parent ion of interest was first isolated by applying 
an appropriate waveform across the end cap electrodes of the ion trap to resonantly eject all trapped ions, except those ions of the $\mathrm{m} / \mathrm{z}$ ratio of interest. The isolated ions were then subjected to a supplementary AC signal to resonantly excite them and so cause collision induced dissociation (CID). The excitation time used was $30 \mathrm{~ms}$ and $12 \%$ to $15 \%$ activation amplitude (0.6-0.75 V lab) was used for all the CID experiments. All the spectra were recorded under identical experimental conditions for isomers, and averages of 30 scan. All the samples were infused into the ESI source at a flow rate of $5 \mu \mathrm{L} / \mathrm{min}$ by using an in-built syringe pump.

\section{Theoretical Calculations}

Density functional methods (DFT) were used to study the stability of the ternary metal-complexes of amino acids. All calculations were carried out in the gas phase using ${ }^{\circ}$ the ${ }^{\circ}$ Gaussian $^{\circ} 03 \mathrm{w}^{\circ}$ software $^{\circ}[36]^{\circ}{ }^{\circ}$ Geometry ${ }^{\circ}$ optimizations and harmonic frequencies calculations were performed on the metal-ligand complex [M $\mathrm{M}^{\mathrm{II}}$ (reference)(D or L-analyte) $]^{+}$using the B3LYP method with 6-31G(d) basis set applied to $\mathrm{C}, \mathrm{N}, \mathrm{O}$, and $\mathrm{H}$ atoms and the LANL2DZ basis set was used to place an effective core potential (ECP) on the metal center and on iodine. LANL2DZ basis set has been used earlier in the study of transition-metal ${ }^{\circ} \mathrm{complexes}^{\circ}[37]^{\circ} .^{\circ} \mathrm{In}^{\circ} \mathrm{Cal}$ culations ${ }^{\circ}$ involving ECPs, only valence electrons and outer-core electrons are considered because they are mainly responsible for bonding interactions. The structures were characterized as energy minima by frequency analysis. Zero point vibrational energy (ZPVE) corrected relative energies are reported. The Ni complex has a charge of +1 and is assumed to be in the singlet ground state while the $\mathrm{Cu}$ complex also with +1 charge is assumed to be in the doublet ground state.

\section{Results and Discussion}

Typical ESI mass spectra of a solution mixture containing a reference (L-tyrosine, 3-iodo-L-tyrosine, or 3,5diiodo-L-tyrosine), analyte (D- or L-amino acid) and metal halide $\left(\mathrm{MCl}_{2}, \mathrm{M}=\mathrm{Ni}\right.$ or $\left.\mathrm{Cu}\right)$ comprises several types of dimeric and trimeric adduct ions. The M(II) bound dimers include homodimer $\left[\mathrm{M}(\mathrm{ref})_{2}-\mathrm{H}\right]^{+}$and heterodimer $[\mathrm{M}(\mathrm{ref})(\mathrm{A})-\mathrm{H}]^{+}$ion formed by deprotonation of one of the reference or analyte. Two types of trimeric ions are observed in the spectra, corresponding to $\left[\mathrm{M}(\mathrm{ref})_{2}(\mathrm{~A})-\mathrm{H}\right]^{+}$and $\left[\mathrm{M}(\mathrm{A})_{2}(\mathrm{ref})-\mathrm{H}\right]^{+}$, which are formed by deprotonation of one of the reference or analyte while the others coordinate to M(II). These trimeric ions are free from the contribution of other multiple charged ions by the fact that the zoom scan of these trimeric complex ions shows no additional peak with an isotopic mass difference of 0.5 or less, and isotopic distribution of these ions is comparable with their simulated spectra. Since deprotonation can occur from any of the reference or analyte, there will be many structures possible for the $\mathrm{M}(\mathrm{II})$ trimeric complex ion composed of two reference and one analyte amino acid. As ${ }^{\circ}$ Cooks $^{\circ}$ et $^{\circ}$ al. 921$]^{\circ}$ pointed ${ }^{\circ}$ out, the ${ }^{\circ}$ distinction between the structures of trimeric ions is not important for the study, but the different stabilities of the two diastereomeric dimeric complexes that are produced by trimeric ion dissociation are important in chiral discrimination. The CID spectra of the trimeric complex ions exclusively result in two fragment ions ( $\mathbf{a}$ and $\mathbf{b}$ ) corresponding to the loss of a reference amino acid (a) and loss of analyte amino acid (b) (Scheme 1). The relative abundances of the two fragments are different for the spectra of trimeric complex ions from two enantiomeric analytes. The difference in energy between the diastereomeric ions $\left[M(\text { ref })\left(A_{D}\right)-H\right]^{+}$and $\left[M(\text { ref })\left(A_{L}\right)-H\right]^{+}$ could be responsible for the observed differences in the relative abundance ratios.

At first, we carried out experiments using L-Tyr as the reference and $\mathrm{Ni}$ as the central metal ion, for discriminating the D- and L-isomers of naturally occurring amino acids. The trimeric complex ions formed from both D- and L-amino acids were subjected for CID experiments, and most of the combinations showed the two expected fragment ions (a and $\mathbf{b}$ ). The spectra of trimeric complex ion with Arg, Asn, Cys, Gln, His, Lys, Met, and Trp show only the fragment ion due to the loss of reference, and the other fragment ion due to the loss of amino acid is negligible, which makes difficult the accurate measurement of abundance ratio. In all these cases the dissociation favors the loss of reference but not the analyte, suggesting higher $\mathrm{Ni}$ ion affinity for Arg, Asn, Cys, Gln, His, Lys, Met, and Trp when compared to Tyr. For all the successful cases, the relative abundance ratios of the two fragment ions formed during the dissociation of trimeric cluster ion from both D- and L-amino acids are used to measure the $R_{\text {chiral }}$ values and they $^{\circ}$ are $^{\circ}$ summarized $^{\circ}$ in $^{\circ}$ Table $^{\circ} 1 .^{\circ}$ These $^{\circ}$ results $^{\circ}$ are

Table 1. $R_{\text {chiral }}$ values for the amino acids using tyrosine and iodinated tyrosine as the reference and $\mathrm{Ni}$ as central metal ion*

\begin{tabular}{lcccc}
\hline Amino acid & $\begin{array}{c}\text { Tyrosine } \\
\pm \mathrm{SD}\end{array}$ & $\begin{array}{c}\text { 3-lodo } \\
\text { L-tyrosine } \\
\pm \mathrm{SD}\end{array}$ & $\begin{array}{c}\text { 3,5-Diiodo } \\
\text { L-tyrosine } \\
\pm \mathrm{SD}\end{array}$ & $\begin{array}{c}\text { Cooks } \\
{[21]}\end{array}$ \\
\hline \hline Phenylalanine & $1.9 \pm 0.1$ & $2.8 \pm 0.2$ & $4.5 \pm 0.1$ & 2.35 \\
Tyrosine & - & $2.1 \pm 0.2$ & $5.2 \pm 0.6$ & 3.04 \\
Alanine & $1.1 \pm 0.1$ & $1.4 \pm 0.2$ & $2.0 \pm 0.1$ & 1.22 \\
Isoleucine & $2.0 \pm 0.1$ & $3.2 \pm 0.1$ & $6.0 \pm 0.2$ & 1.65 \\
Leucine & $1.4 \pm 0.1$ & $2.2 \pm 0.1$ & $2.8 \pm 0.2$ & 1.21 \\
Serine & $1.1 \pm 0.1$ & $1.3 \pm 0.1$ & $2.4 \pm 0.2$ & 1.11 \\
Threonine & $1.2 \pm 0.1$ & $1.9 \pm 0.2$ & $2.9 \pm 0.3$ & 1.18 \\
Proline & $2.3 \pm 0.1$ & $2.9 \pm 0.4$ & - & 1.77 \\
Valine & $1.7 \pm 0.1$ & $3.3 \pm 0.1$ & $5.5 \pm 0.2$ & 1.58 \\
Aspartic acid & $3.3 \pm 0.4$ & $1.9 \pm 0.2$ & $1.4 \pm 0.1$ & 2.38 \\
Glutamic acid & $3.1 \pm 0.4$ & $1.9 \pm 0.2$ & $1.9 \pm 0.2$ & 2.65 \\
\hline
\end{tabular}

${ }^{*}$ CID activation level is optimized and kept constant for all measurements of enantiomers. The standard deviation (SD) is based on triplicate measurements on different days.

${ }^{a} R_{\text {chiral }}$ values obtained from the dissociation of $\mathrm{Ni}$ bound trimeric cluster ions of amino acid and reference amino acid (L-tryptophan for Phe and Tyr and L-phenyl alanine for other amino acids). 

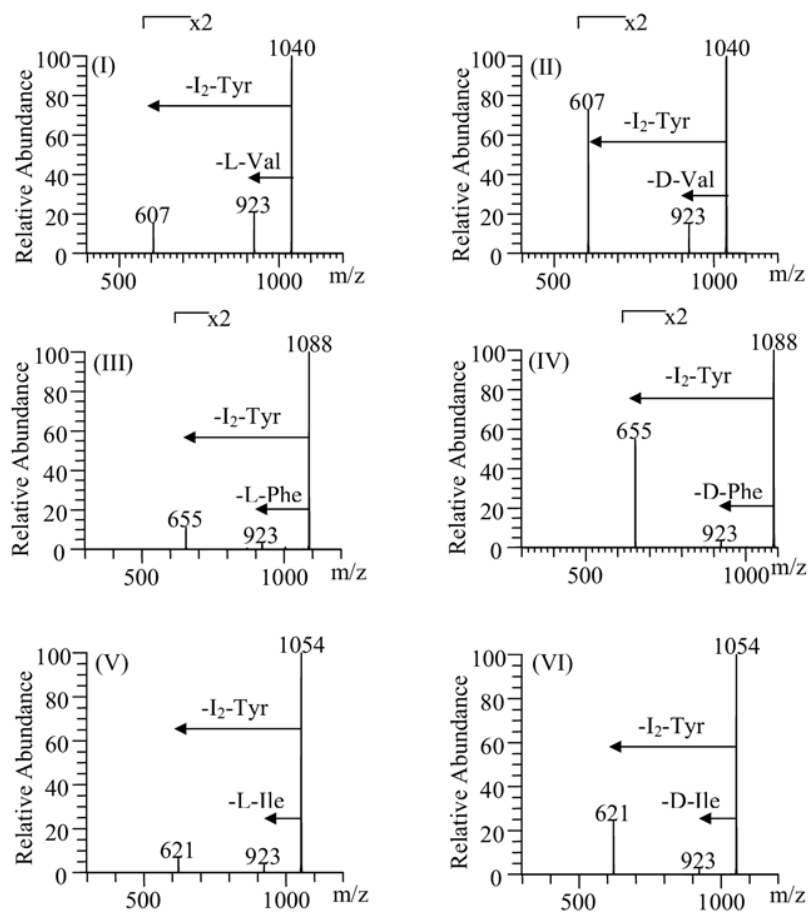

Figure 1. CID-product ion mass spectra of $\left[\mathrm{Ni}^{\mathrm{II}}\left(\mathrm{L}-\mathrm{I}_{2}-\mathrm{Tyr}\right)_{2}\right.$ (AA) $-\mathrm{H}]^{+}$ions $\left(\mathrm{L}-\mathrm{I}_{2}-\mathrm{Tyr}=3,5\right.$-diiodo-L-Tyrosine), I) $\mathrm{L}-$ Val, II) D - Val, III) L - Phe, IV) D-Phe, V)L - Ile, VI) D - Ile.

comparable ${ }^{\circ}$ to ${ }^{\circ}$ the ${ }^{\circ}$ values $^{\circ}$ reported ${ }^{\circ}$ by $^{\circ}$ Cooks $^{\circ}$ et $^{\circ}$ al..$^{\circ}[21]$ for the discrimination of some of the amino acids by using Phe or Tyr as a reference and $\mathrm{Ni}$ as the central metal ion.

With these results with Tyr, we further moved on to the use of iodinated L-tyrosines, viz., 3-iodo-L-tyrosine and 3,5-diiodo-L-tyrosine as references aiming to explore the influence of the iodine substituents on aromatic ring in chiral discrimination. The CID experiments were performed on the trimeric cluster ions of iodinated L-tyrosine and amino acids as described above. As discussed earlier, the present method could not be applied to Arg, Asn, Cys, Gln, His, Lys, Met, Pro, and Trp because MS/MS experiments of trimeric cluster ion with these amino acids overwhelmingly favor the loss of reference, not the analyte. The $R_{\text {chiral }}$ values obtained for all the successful amino acids are summarized in Table 9 . The experimental ${ }^{\circ}$ results $^{\circ}$ show $^{\circ}$ that ${ }^{\circ}$ the iodinated L-tyrosines can also successfully discriminate the studied amino acids. There is considerable increase in chiral selectivity for aliphatic, hydroxy, and aromatic amino acids going from L-Tyr to 3-iodo-L-tyrosine and to 3,5-diiodo-L-tyrosine as references, whereas for the acidic amino acids the selectivity somewhat decreased. Aromatic amino acids (Tyr and Phe) and aliphatic amino acids with larger alkyl side-chain at the $\beta$ carbon (Ile and Val) show best chiral selectivity with iodinated L-tyrosines $^{\circ}$ as $^{\circ}$ references $^{\circ}\left(\right.$ Figure $\left.^{\circ} 1\right) .^{\circ}$ In $^{\circ}$ case $^{\circ}$ of $^{\circ}$ acidic amino acids (Asp), the $R_{\text {chiral }}$ value decreases from tyrosine to 3-iodo-L-tyrosine and to 3,5-diiodo-Ltyrosine, and this may be due to contribution from different structures for the complex ion of interest where the extra $-\mathrm{COOH}$ (as such or after deprotonation) of the amino acid can also be involved in the complex formation. Nevertheless, chiral discrimination for most of the amino acids studied increased as the number of iodine atoms increased on the aromatic ring of the reference (Tyr). The degree of discrimination using iodinated L-tyrosines as reference is even better than that obtained in the earlier reports for some of the amino ${ }^{\circ} \operatorname{acids}^{\circ}[21]$.

We carried out all the above experiments replacing $\mathrm{Ni}$ by $\mathrm{Cu}$ and found that the chiral discrimination is much $^{\circ}$ better $^{\circ}\left(\right.$ Table $\left.^{\circ} 2\right){ }^{\circ}$ All $^{\circ}$ the ${ }^{\circ}$ analyte ${ }^{\circ}$ amino ${ }^{\circ}$ acids, except Cys, form abundant trimeric complex ions; Cys gets oxidized to cystine by $\mathrm{Cu}(\mathrm{II})$ ions in solution rather than forming the corresponding $[\mathrm{Cu}(\mathrm{Cys})(\mathrm{ref}) \mathrm{n}-\mathrm{H}]^{+}$ ions, where $n=1$ and 2. Similar behavior of Cys was reported ${ }^{\circ}$ by $^{\circ} \mathrm{Cooks}^{\circ} \mathrm{et}^{\circ}$ al. $^{\circ}$ also $^{\circ}[20]^{\circ}{ }^{\circ} \mathrm{Now}^{\circ}$ the $^{\circ}$ use $^{\circ}$ of iodinated L-tyrosines as the references enhanced the chiral discrimination more than that reported until now for $^{\circ}$ maximum $^{\circ}$ number $^{\circ}$ of $^{\circ}$ amino $^{\circ}$ acids $^{\circ}\left[10^{\circ}-12,{ }^{\circ} 20^{\circ}-21\right]$. The CID spectra of Val using all three references are

Table 2. $R_{\text {chiral }}$ values for the amino acids using tyrosine and iodinated tyrosine as the reference and $\mathrm{Cu}$ as central metal ion*

\begin{tabular}{|c|c|c|c|c|c|}
\hline Amino acid & Tyrosine \pm SD & 3-iodo-L-tyrosine $\pm S D$ & 3,5 Diiodo-L-tyrosine $\pm \mathrm{SD}$ & Cooks $^{a}[20]$ & Lebrillab $^{\mathrm{b}}[10]$ \\
\hline Alanine & $1.1 \pm 0.2$ & $2.1 \pm 0.1$ & $2.5 \pm 0.1$ & 2 & 3.5 \\
\hline Leucine & $2.2 \pm 0.1$ & $2.6 \pm 0.1$ & $3.0 \pm 0.3$ & 2.3 & 4.2 \\
\hline Isoleucine & $4.5 \pm 0.3$ & $6.9 \pm 0.3$ & $10.4 \pm 0.2$ & 4.8 & 4.1 \\
\hline Valine & $5.0 \pm 0.2$ & $7.3 \pm 0.1$ & $10.3 \pm 0.1$ & 4.5 & 3.8 \\
\hline Proline & $5.2 \pm 0.1$ & $6.1 \pm 0.3$ & $7.0 \pm 0.1$ & 5.3 & 5.3 \\
\hline Serine & $1.3 \pm 0.1$ & $2.5 \pm 0.2$ & $4.0 \pm 0.3$ & 1.5 & 1.2 \\
\hline Threonine & $1.4 \pm 0.1$ & $3.0 \pm 0.2$ & $5.4 \pm 0.2$ & 1.8 & 2.6 \\
\hline Aspartic acid & $2.2 \pm 0.1$ & $1.9 \pm 0.1$ & $1.4 \pm 0.1$ & 2.7 & 2.7 \\
\hline Glutamic acid & $3.0 \pm 0.2$ & $2.5 \pm 0.3$ & $3.3 \pm 0.2$ & 3.1 & 3.4 \\
\hline Phenylalanine & $7.2 \pm 0.3$ & $10.2 \pm 0.6$ & $13.0 \pm 0.4$ & 8.3 & 2.1 \\
\hline Tyrosine & - & $11.6 \pm 0.6$ & $15.8 \pm 0.3$ & 11 & 1.2 \\
\hline
\end{tabular}

*CID activation level is optimized and kept constant for all measurements of enantiomers. The standard deviation (SD) is based on triplicate measurements on different days.

${ }^{a} R_{\text {chiral }}$ values obtained from the dissociation of $\mathrm{Cu}$ bound trimeric cluster ions of amino acid and reference amino acid (L-tryptophan for Phe and Tyr and L-phenyl alanine for other amino acids).

${ }^{b} k_{L} / k_{D}$ (enantioselectivity) obtained in the gas phase exchange reactions of an achiral amine and amino acid with $\beta$-CDs. 

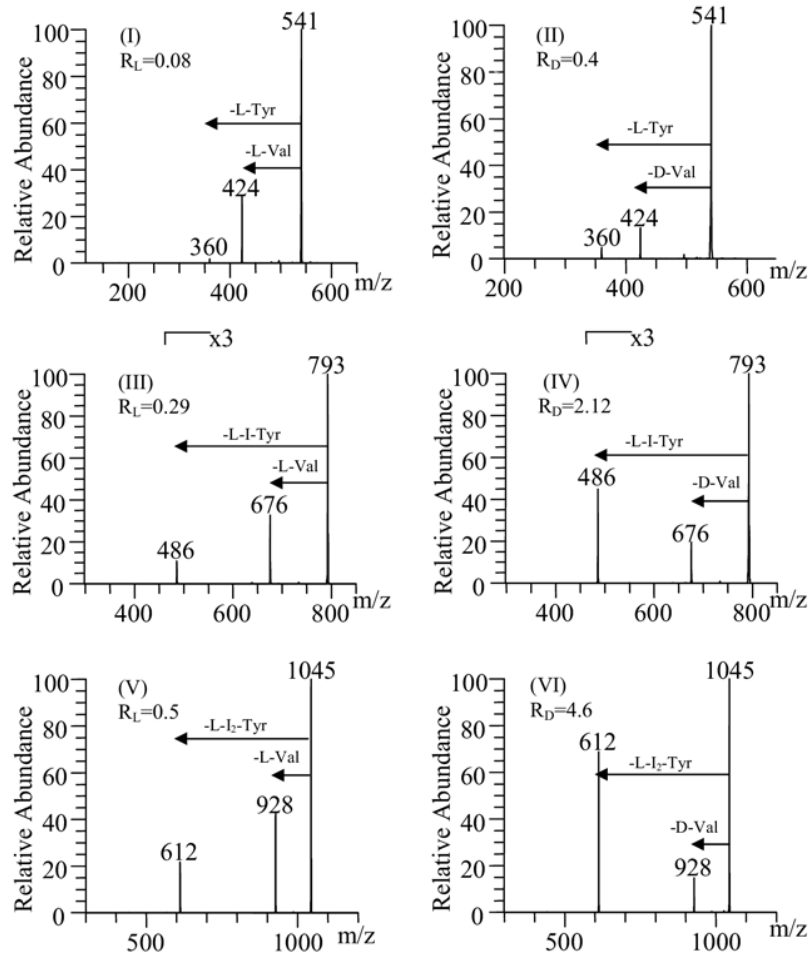

Figure 2. CID product ion mass spectra of $\left[\mathrm{Cu}^{\mathrm{II}}(\mathrm{ref})_{2}(\mathrm{Val})-\mathrm{H}\right]^{+}$ ions with L- Tyrosine (I and II), 3-iodo-L Tyrosine (III and IV) and 3,5- diiodo-L-Tyrosine(V and VI) as references.

shown ${ }^{\circ}$ in $^{\circ}$ Figure $^{\circ} 2^{\circ}$ as $^{\circ}$ an $^{\circ}$ example..$^{\circ}$ Among ${ }^{\circ}$ the ${ }^{\circ}$ aliphatic amino acids, the chiral discrimination increased as the steric crowding increased on the $\beta$ carbon. For example, when 3,5-diiodo-L-Tyr was used as the reference, Ala showed the least chiral discrimination (excluding acidic amino acids) due to the presence of a simple methyl group. The chiral selectivity among Ala, Leu, Val, and Ile is in the order of Ala $<$ Leu $<$ Val $\leq$ Ile. Spectra of $\mathrm{Val}^{\circ}$ and $^{\circ} \mathrm{Ile}^{\circ}$ are $^{\circ}$ shown $^{\circ}$ in $^{\circ}$ the $^{\circ}$ Figure $^{\circ} 2^{\circ}$ and $^{\circ}$ Figure $^{\circ} 3$, respectively. L-proline, containing a rigid cyclic structure, also shows better chiral selectivity (7.0) than Ala and Leu.

Although amino acids with polar groups such as hydroxyl (Ser and Thr) were shown to display fair chiral resolution in ligand exchange chromatography, poor selectivity was reported in the earlier gas-phase chiral $^{\circ}$ discrimination ${ }^{\circ}$ experiments ${ }^{\circ}\left[10^{\circ}-12,{ }^{\circ} 20^{\circ}-21\right] .^{\circ}$ Here we find a better degree of chiral selectivity for Ser and $\operatorname{Thr}^{\circ}\left(\text { see }^{\circ} \operatorname{Tables}^{\circ} 1^{\circ} \text { and }{ }^{\circ} 2\right)^{\circ}$ using $^{\circ}$ iodinated $^{\circ} L_{\text {-tyrosines }}^{\circ}$ as the ${ }^{\circ}$ reference $^{\circ}\left(\right.$ Figure $\left.^{\circ} 3\right)$.

Yamauchi ${ }^{\circ}$ et $^{\circ}$ al. $^{\circ}[38]^{\circ}$ proposed $^{\circ}$ better $^{\circ}$ stabilization $^{\circ}$ of $\mathrm{Cu}$ (II) ternary complexes of aromatic diamine and aromatic amino acids due to intramolecular $\pi$ - $\pi$ stacking interaction between the aromatic rings of the aromatic diamine and aromatic amino acid. In similar lines, Cooks ${ }^{\circ} t^{\circ}$ al. ${ }^{\circ}[20]^{\circ}$ explained ${ }^{\circ}$ the ${ }^{\circ}$ igher ${ }^{\circ}$ chiral $^{\circ}$ recognition of amino acids when aromatic amino acid was used as the reference. They proposed that the $\pi-\pi$ stacking interactions are likely to be between the aromatic ring of the reference ligand and the carboxylate group of the analyte. The conformation in which the aromatic ring is located above the carboxylate group allows the electron flow between the aromatic ring and the carboxylate group, which coordinates to the $\mathrm{Cu}(\mathrm{II})$ cation via a charge-transfer (CT) interaction. When L-amino acid is used as the analyte, the group on $\alpha$-asymmetric carbon aligns with the same side of the aromatic ring of the reference, which disrupts the $\pi$ - $\pi$ stacking interactions between the aromatic ring of the reference and carbonyl group of the analyte, whereas such disruptions are absent when D-amino acid is used as the analyte because the side-chain group is away from the aromatic ring of the reference. Thus in the present case also dimeric complexes of D-amino acid (analyte) are more stable than that of the L-amino acids, which is consistent with the earlier observations. As the size of the alkyl group on the $\beta$-carbon of the analyte increases, i.e., $2 \mathrm{H},(\mathrm{H}) \mathrm{CH}\left(\mathrm{CH}_{3}\right)_{2},\left(\mathrm{CH}_{3}\right)_{2}$, and $\left(\mathrm{CH}_{3}\right)\left(\mathrm{C}_{2} \mathrm{H}_{5}\right)$ in the series Ala, Leu, Val, and Ile respectively, preference for the heterochiral complexes over the homochiral ones results in large increase in the corresponding $R_{\text {chiral }}$ values $(2.5,3.0,10.3$, and 10.4, respectively). Despite the fact that Leu and Ile have the same number of carbon atoms, the chiral selectivity for Ile is much greater than that for Leu, which may be attributed to the presence of two alkyl groups in the $\beta$-carbon of Ile.

Yamauchi $^{\circ}$ et $^{\circ}$ al. $^{\circ}\left[39{ }^{\circ} 41\right]^{\circ}$ extensively $^{\circ}$ studied $^{\circ}$ the solution phase structures and stabilities of ternary $\mathrm{Cu}(\mathrm{II})$ complexes of aromatic amino acids and aro-
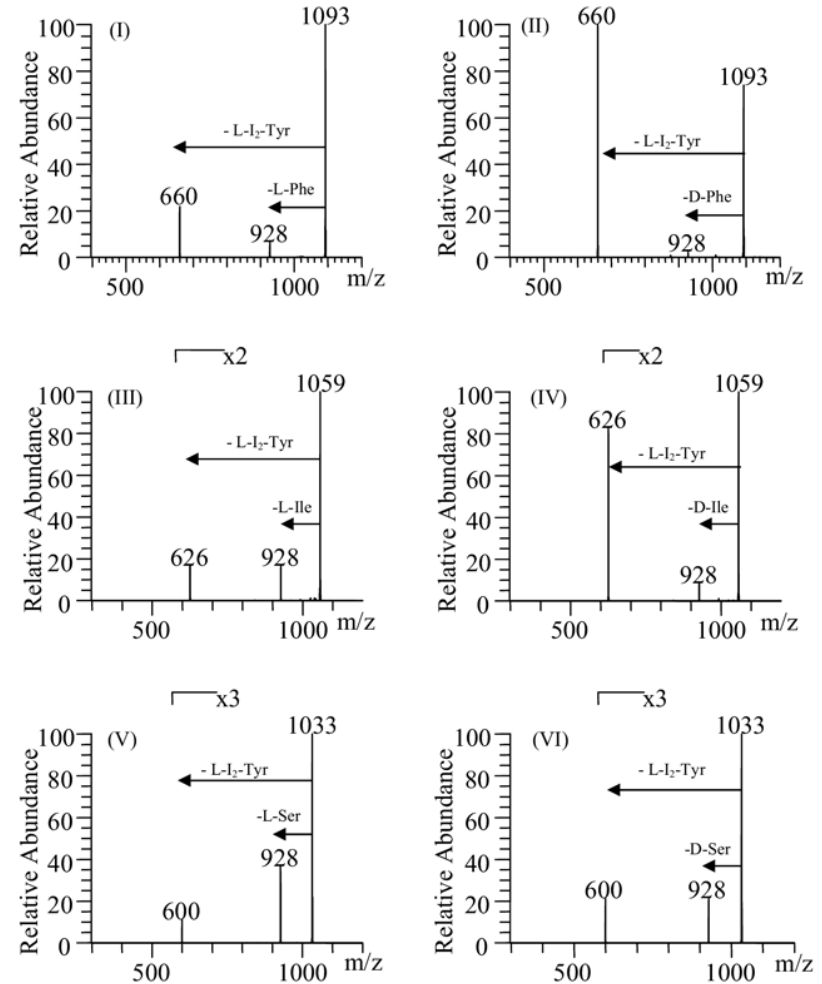

Figure 3. CID-product ion mass spectra of $\left[\mathrm{Cu}^{\mathrm{II}}\left(\mathrm{L}-\mathrm{I}_{2}-\mathrm{Tyr}\right)_{2}\right.$ (AA) $-\mathrm{H}]^{+}$ions $\left(\mathrm{L}-\mathrm{I}_{2}-\mathrm{Tyr}=3,5\right.$-diiodo-L-Tyrosine), I) $\mathrm{L}-$ Phe, II) D - Phe, III) L - Ile, IV) D - Ile, V)L - Ser, VI) D - Ser. 
matic diamines with different substituents (electronwithdrawing/-donating) on the aromatic ring of the amino acid. They found that when electron-donating substituent was present on the aromatic ring of the amino acid, the $\pi$ electron density increased, and thereby the stability of the complex increased. Electron withdrawing groups behave in the opposite direction. It suggests that the metal coordinated aromatic diamine serves as CT acceptor, whereas the side-chain aromatic ring of coordinated amino acids acts as a CT donor. However, ${ }^{\circ}$ recently ${ }^{\circ}[39]^{\circ}$ it $^{\circ}$ was $^{\circ}$ also $^{\circ}$ found ${ }^{\circ}$ that ${ }^{\circ}$ when halogen substituent is present on the aromatic ring of the amino acid, it gives exceptional stabilization to the $\mathrm{Cu}$ ternary complex and stability is found to increase with the increase of the polarizability of the halogen atom (fluorine to bromine). They concluded that as the polarizability of halogen substituent on the aromatic amino acid increases (fluorine to bromine), the van der Waals interaction between the halogen atom and $\pi$ electrons on the other aromatic ring increases and contributes towards the increased complex stabilization. Their study of $\mathrm{Cu}$ ternary complexes of aromatic diamines and iodinated tyrosine (3-iodo-L-tyrosine or 3,5-diiodo-L-tyrosine) has revealed that the presence of iodo group on the aromatic ring of the aromatic amino acid does not promote CT interaction but is involved directly in weak interactions with the aromatic diamine $[40,41]$.

In the present study, the chiral selectivity of amino acids using Tyr as the reference is close to that reported using Phe as the reference. For example, $R_{\text {chiral }}$ values for the Ile and Val with Phe as reference are 4.8 and 4.5, respectively, and with Tyr as reference the values are 4.5 and 5 , respectively, which suggests that the electron donating group $(-\mathrm{OH})$ on the aromatic ring of the reference amino acid (Tyr) does not influence the $\pi-\pi$ stacking interactions in the diastereomeric complexes. But, when iodinated L-tyrosines (3-iodo-L-tyrosine or 3,5-diiodo-L-tyrosine) were used as the reference, the chiral selectivity of amino acids gradually increased with number of iodine substituents. In the case of $\mathrm{L}$-analyte, the side-chain is nearer to the aromatic ring of the reference, which disrupts the $\pi-\pi$ stacking interactions between the aromatic ring of the reference and the carbonyl group of the analyte. The close proximity of the iodine atoms (van der Waals radius $=1.967 \mathrm{~A}^{\circ}$ ) and the side-chain of the L-analyte leads to larger steric interaction and this leads to the destabilization of the complex involving the L-analyte more compared with the Danalyte. We further carried out theoretical calculations on the stabilities of the dimeric $\left[\mathrm{M}^{\mathrm{II}}(\mathrm{ref})(\mathrm{A})\right]^{+}$complexes to understand the experimental observations.

\section{Computational Studies}

Density functional methods (DFT) are used to study the stability of the ternary diastereomeric metal complexes of amino acids. All initial calculations were carried out mainly for Ni metal bound dimeric complexes of D- and

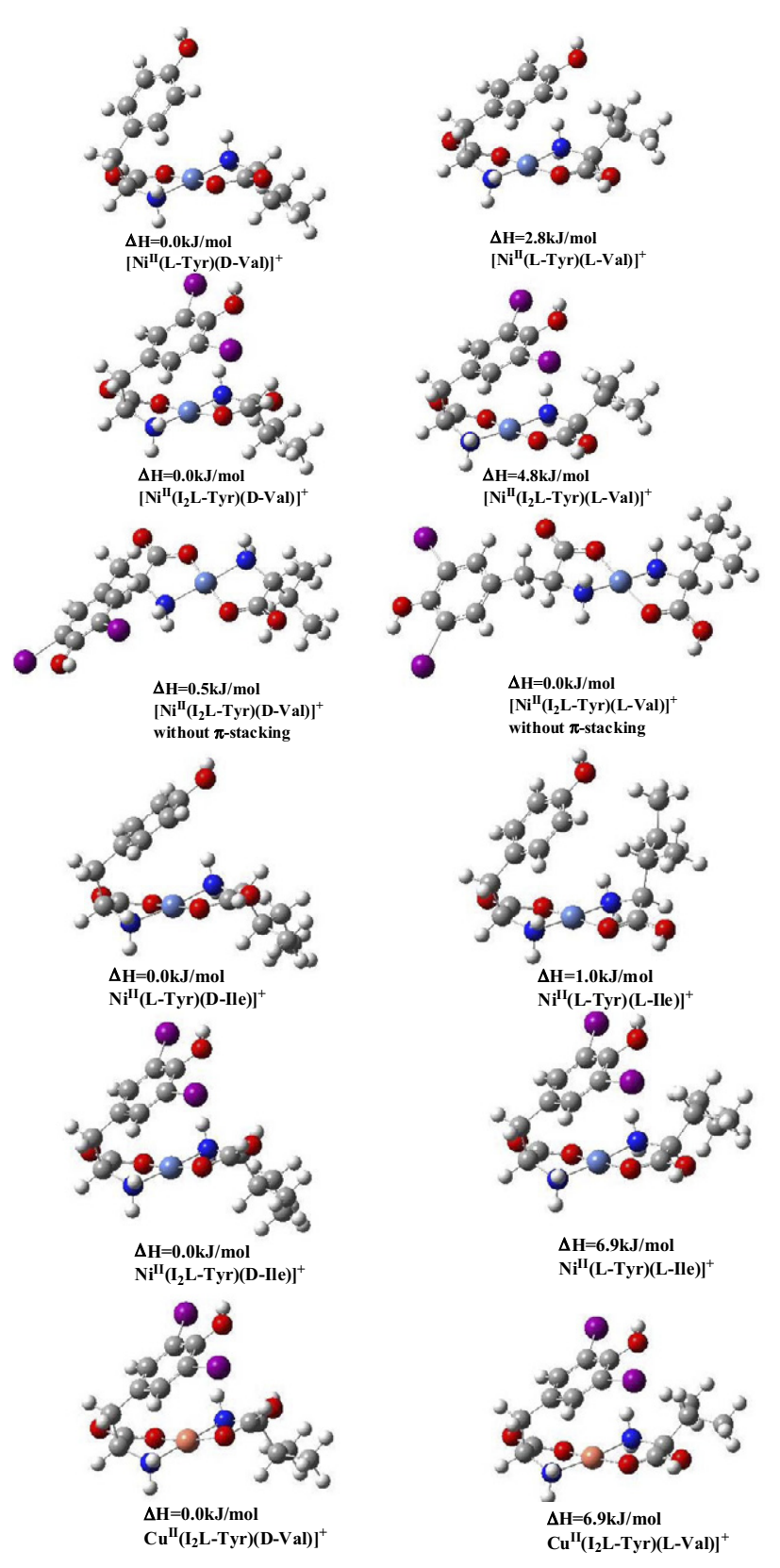

Figure 4. Final optimized geometries for D- and L-isomers of the $\left[\mathrm{M}^{\mathrm{II}}(\text { reference)(D, L-analyte) }]^{+}\right.$complex obtained using B3LYP/6$31 \mathrm{G}(\mathrm{d})$ for $\mathrm{C}, \mathrm{O}, \mathrm{N}, \mathrm{H}$ atoms and an effective core potential and LANL2DZ basis set on $\mathrm{Ni}, \mathrm{Cu}$, and I. All energies reported are ZPVE corrected.

L-Val as the analyte and L- Tyr as the reference amino acid. A survey of the $\mathrm{Ni}$ and $\mathrm{Cu}$ complexes in the Cambridge ${ }^{\circ}$ Structural ${ }^{\circ}$ Database ${ }^{\circ}(\mathrm{CSD})^{\circ}[42]^{\circ}{ }^{\circ}$ reveals ${ }^{\circ}$ that they prefer square planar geometry in which the amino group and carbonyl group of the amino acids are coordinated to the metal. Due to the conformational flexibility in this complex, various starting geometries were tried out. Chelation of the amino and the carbonyl groups of the reference and the analyte amino acids with the metal atom can have two possible conformations. The amino/carbonyl groups of both the amino 
acids can lie on one side of the complex (cis) or on the opposite side (trans). We carried out calculations for both conformations and found that the trans conformation is more stable. From the experimental data (vide supra) it is clearly seen that there is a loss of hydrogen from the amino acid, which could be either from the analyte or from the reference. To check this we carried out geometry optimization of both complexes; one with the loss of hydrogen from reference and the other with the loss of hydrogen from analyte. We found that the complex with the loss of hydrogen from reference was more stable, hence this was considered for further studies. We also obtained two major orientations arising due to the phenyl group of Tyr. These are, one with $\pi$-stacking and the other without $\pi$-stacking to the metal atom. We found that the $\pi$-stacked isomers were more stable than the isomers without the $\pi$-stacking. The above-obtained conformations for Val as the analyte were also retained for the calculations with Ile as the analyte. The final structures and the relative energies $^{\circ}$ obtained ${ }^{\circ}$ are $^{\circ}$ shown $^{\circ}{ }^{\circ}{ }^{\circ}$ Figure $^{\circ} 4$.

It is seen that the dimeric complex with $\mathrm{D}-\mathrm{Val}$ is more stable than L-Val by $2.8 \mathrm{~kJ} / \mathrm{mol}$ when Tyr is used as the reference and $\mathrm{Ni}$ as central metal ion. In the case of 3,5-diiodo-L-tyrosine as the reference, the relative energy difference increases to $4.8 \mathrm{~kJ} / \mathrm{mol}$. Geometrical parameters ${ }^{\circ}$ are $^{\circ}$ shown $^{\circ}$ in ${ }^{\circ}$ Table $^{\circ} .^{\circ}{ }^{\circ}$ All ${ }^{\circ}$ these ${ }^{\circ}$ are ${ }^{\circ}{ }^{\circ}$ good agreement with the experimental data. To understand the effect of interactions in destabilizing the L-isomer, we compare the non- $\pi$-stacked conformations of $\left[\mathrm{Ni}^{\mathrm{II}}\left(\mathrm{I}_{2} \mathrm{Tyr}\right)\left(\mathrm{D},{ }^{\circ} \mathrm{L}-\mathrm{Val}\right)\right]^{+}$. These ${ }^{\circ}{ }^{\circ}{ }^{\circ}{ }^{\circ}$ also ${ }^{\circ}$ shown ${ }^{\circ}$ in ${ }^{\circ}$ Figure 4. We ${ }^{\circ}$ notice that ${ }^{\circ}$ the $e^{\circ}$ energy ${ }^{\circ}$ differences ${ }^{\circ}$ between ${ }^{\circ}$ the ${ }^{\circ} \mathrm{D}$ and L-forms without $\pi$-stacking are negligible (less than $1 \mathrm{~kJ} / \mathrm{mol}$ ). Thus, in the case of $\pi$-stacked conformations, alkyl group of analyte having different orientation in Dand L-forms is mainly responsible for the different stability of the diastereomeric complexes. The difference in the stability further increases from the Tyr to 3,5-diiodo-Tyr due to iodine substitution. The metal to both the iodine atoms distance in the D-Val is almost equidistant (around 5.401 to $5.423 \mathrm{~A}^{\circ}$ ). But in the case of $\mathrm{L}-\mathrm{Val}$, one of the iodine atoms is far away $\left(5.626 \mathrm{~A}^{\circ}\right)$ from the metal, while the other iodine atom is nearer $\left(5.195 \mathrm{~A}^{\circ}\right)$. In case of the $\mathrm{L}-\mathrm{Val}$ the alkyl groups point nearer to the phenyl ring that may cause steric interaction between iodine and the alkyl group of the L-Val. The extent of steric interaction with both iodine atoms can be different depending on the orientation of the alkyl group. In the case of D-Val steric interaction between the iodine atoms and alkyl group is unlikely as it points away from the phenyl ring of the reference amino acid. The distances between the $\beta$-carbon atom of $\mathrm{L}-\mathrm{Val}$ and the two iodine atoms are $4.913 \mathrm{~A}^{\circ}$ and 5.496 $\mathrm{A}^{\circ}$ whereas in the case of D-Val the distances are 7.001 $\mathrm{A}^{\circ}$ and $6.878 \mathrm{~A}^{\circ}$. Thus it shows the close proximity of the alkyl group and iodine atoms in case of the L-Val.

Table 3. Optimized bond lengths $(\AA)$ and angles (deg) for metal (M)-amino acid complexes at B3LYP/6-31G(d) [C,N,O,H] and LANL2DZ [Ni, $\mathrm{Cu}, \mathrm{I}]$ basis sets obtained in this study

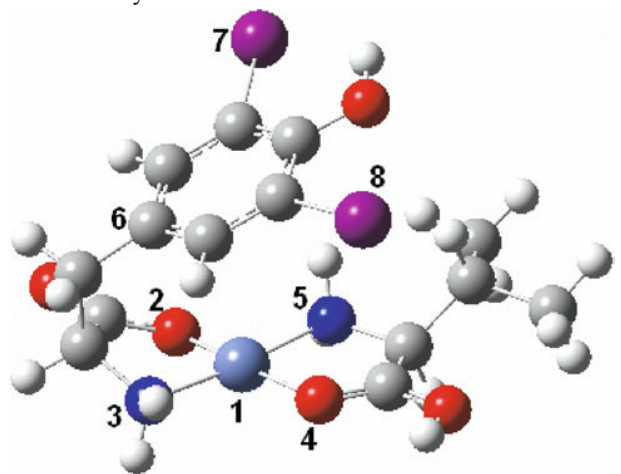

\begin{tabular}{|c|c|c|c|c|c|c|c|c|c|c|c|}
\hline Molecule & $\begin{array}{c}\mathrm{M}_{1}-\mathrm{O}_{2} \\
\left(\mathrm{~A}^{0}\right)\end{array}$ & $\begin{array}{c}M_{1}-N_{3} \\
\left(A^{0}\right)\end{array}$ & $\begin{array}{c}\mathrm{M}_{1}-\mathrm{O}_{4} \\
\left(\mathrm{~A}^{\mathrm{O}}\right)\end{array}$ & $\begin{array}{c}M_{1}-N_{5} \\
\left(A^{0}\right)\end{array}$ & $\begin{array}{c}\mathrm{O}_{2}-\mathrm{M}_{1}- \\
\mathrm{N}_{3}(\mathrm{deg})\end{array}$ & $\begin{array}{c}\mathrm{N}_{3}-\mathrm{M}_{1}- \\
\mathrm{O}_{4}(\mathrm{deg})\end{array}$ & $\begin{array}{c}\mathrm{O}_{4}-\mathrm{M}_{1}- \\
\mathrm{N}_{5}(\mathrm{deg})\end{array}$ & $\begin{array}{l}\mathrm{N}_{5}-\mathrm{M}_{1}- \\
\mathrm{O}_{2}(\mathrm{deg})\end{array}$ & $\begin{array}{c}{ }^{*} \mathrm{M}_{1}-\mathrm{C}_{6} \\
\left(\mathrm{~A}^{0}\right)\end{array}$ & $\begin{array}{c}{ }^{*} \mathrm{M}_{1}-\mathrm{I}_{7} \\
\left(\mathrm{~A}^{0}\right)\end{array}$ & $\begin{array}{c}{ }^{*} \mathrm{M}_{1}-\mathrm{I}_{8} \\
\left(\mathrm{~A}^{0}\right)\end{array}$ \\
\hline$\left[\mathrm{Ni}^{\prime \prime}(\mathrm{L}-\mathrm{Tyr})(\mathrm{D}-\mathrm{Val})\right]^{+}$ & 1.812 & 1.926 & 1.948 & 1.942 & 85.9 & 99.2 & 84.2 & 90.9 & 3.125 & - & - \\
\hline$\left[\mathrm{Ni}^{\prime \prime}(\mathrm{L}-\mathrm{Tyr})(\mathrm{L}-\mathrm{Val})\right]^{+}$ & 1.811 & 1.927 & 1.934 & 1.936 & 86.0 & 99.5 & 84.0 & 90.8 & 3.144 & - & - \\
\hline$\left[\mathrm{Ni}^{\prime \prime}\left(\mathrm{I}_{2} \mathrm{~L}-\mathrm{Tyr}\right)(\mathrm{D}-\mathrm{Val})\right]^{+}$ & 1.808 & 1.927 & 1.938 & 1.950 & 86.2 & 98.3 & 84.6 & 90.8 & 3.251 & 5.423 & 5.401 \\
\hline$\left[\mathrm{Ni}^{\prime \prime}\left(\mathrm{I}_{2} \mathrm{~L}-\mathrm{Ty} r\right)(\mathrm{L}-\mathrm{Val})\right]^{+}$ & 1.810 & 1.928 & 1.928 & 1.939 & 86.0 & 98.6 & 84.2 & 91.4 & 3.211 & 5.626 & 5.195 \\
\hline$\left[\mathrm{Ni}^{\prime \prime}(\mathrm{L}-\mathrm{Tyr})(\mathrm{D}-\mathrm{Ile})\right]^{+}$ & 1.812 & 1.926 & 1.949 & 1.942 & 86.0 & 99.1 & 84.2 & 91.0 & 3.132 & - & - \\
\hline$\left[\mathrm{Ni}^{\prime \prime}(\mathrm{L}-\mathrm{Tyr})(\mathrm{L}-\mathrm{lle})\right]^{+}$ & 1.801 & 1.921 & 1.945 & 1.952 & 87.5 & 97.4 & 84.4 & 90.7 & 3.574 & - & - \\
\hline$\left[\mathrm{Ni}^{\prime \prime}\left(\mathrm{I}_{2} \mathrm{~L}-\mathrm{Tyr}\right)(\mathrm{D}-\mathrm{Ile})\right]^{+}$ & 1.809 & 1.926 & 1.936 & 1.951 & 86.1 & 98.2 & 84.7 & 91.0 & 3.275 & 5.474 & 5.408 \\
\hline$\left[\mathrm{Ni}^{\prime \prime}\left(\mathrm{I}_{2} \mathrm{~L}-\mathrm{Tyr}\right)(\mathrm{L}-\mathrm{Ile})\right]^{+}$ & 1.810 & 1.928 & 1.927 & 1.937 & 86.1 & 99.0 & 84.2 & 90.8 & 3.222 & 5.587 & 5.259 \\
\hline $\begin{array}{l}{\left[\mathrm{Cu}^{\prime \prime}\left(\mathrm{I}_{2} \mathrm{~L}-\mathrm{Tyr}\right)(\mathrm{D}-\right.} \\
\mathrm{Val})]^{+}\end{array}$ & 1.894 & 2.025 & 2.049 & 2.061 & 83.9 & 101.9 & 81.2 & 93.2 & 3.176 & 5.168 & 5.457 \\
\hline$\left[\mathrm{Cu}^{\prime \prime}\left(\mathrm{I}_{2} \mathrm{~L}-\mathrm{Tyr}\right)(\mathrm{L}-\mathrm{Val})\right]^{+}$ & 1.895 & 2.025 & 2.044 & 2.046 & 84.0 & 103.1 & 80.2 & 92.9 & 3.150 & 5.539 & 5.223 \\
\hline
\end{tabular}

*Distance between the atoms.

a The numbering system is followed as shown in the figure.

${ }^{\mathrm{b}}$ For the first eight molecules $\mathrm{M}=\mathrm{Ni}$ and for the last two $\mathrm{M}=\mathrm{Cu}$. 
We also studied the system with Ile in place of Val and noticed a similar behavior. The D-Ile complex is more stable by $6.9 \mathrm{~kJ} / \mathrm{mol}$ in the case of 3,5-diiodo-L-tyrosine as the reference. Preliminary calculations on D-, L-Leu with $\mathrm{Ni}$ atom show that the difference in energy between the D- and the L-isomers is around $1.3 \mathrm{~kJ} / \mathrm{mol}$ (without ZPVE correction), which is in good agreement with the experimental value. The difference in energy between the D- and L-isomers of Leu is lesser than the Ile, thereby reproducing the experimental trend.

\section{Quantitative Measurement of Enantiomeric Purities of the Amino Acids}

The large chiral selectivity with the 3,5-diiodo-Ltyrosine as a reference and the sensitive nature of the kinetic method allow quantitative measurement of the optical purity of the amino acids. With a view to checking the suitability of the present method for measurement of optical purity of amino acids, we did quantitative experiments by selecting $\mathrm{Val}$ as the analyte. Figure $^{\circ} 5^{\circ}$ shows $^{\circ}$ the ${ }^{\circ}$ quantitative ${ }^{\circ}$ results $^{\circ}$ for ${ }^{\circ}$ the ${ }^{\circ}$ analysis of $\mathrm{Val}$ enantiomers with 3,5-diiodo-L-tyrosine as the reference and $\mathrm{Cu}(\mathrm{II})$ as the central metal ion. The experiments were performed using L- and Denantiomers of Val with various compositions, 100/0, $98 / 2,90 / 10,75 / 25,50 / 50,25 / 75,10 / 90,2 / 98$, and $0 / 100[(L)-\mathrm{Val} /(D)-\mathrm{Val} \%]$. The natural logarithm of abundance ratio of $\left[\mathrm{Cu}^{\mathrm{II}}(\text { ref })(\mathrm{A})-\mathrm{H}\right]^{+} /\left[\mathrm{Cu}^{\mathrm{II}}(\text { ref })_{2}-\right.$ $\mathrm{H}]^{+}$was plotted as a function of enantiomeric excess $(e e)^{\circ}$ values $^{\circ}$ (Figure 5 ). ${ }^{\circ}$ The ${ }^{\circ}$ results ${ }^{\circ}$ indicate ${ }^{\circ}$ good linearity for the method $\left(R^{2}=0.9997\right)$. By using this calibration curve, we have also determined the enantiomeric excess of Val in six different samples. The experimental results are tabulated ${ }^{\circ}{ }^{\top}{ }^{\top}$ able 4 . The ${ }^{\circ}$ present ${ }^{\circ}$ linearity ${ }^{\circ}{ }^{\circ}{ }^{\circ}{ }^{\circ}$ chiral quantification experiments clearly demonstrate that the kinetic method can be employed to determine enantio-

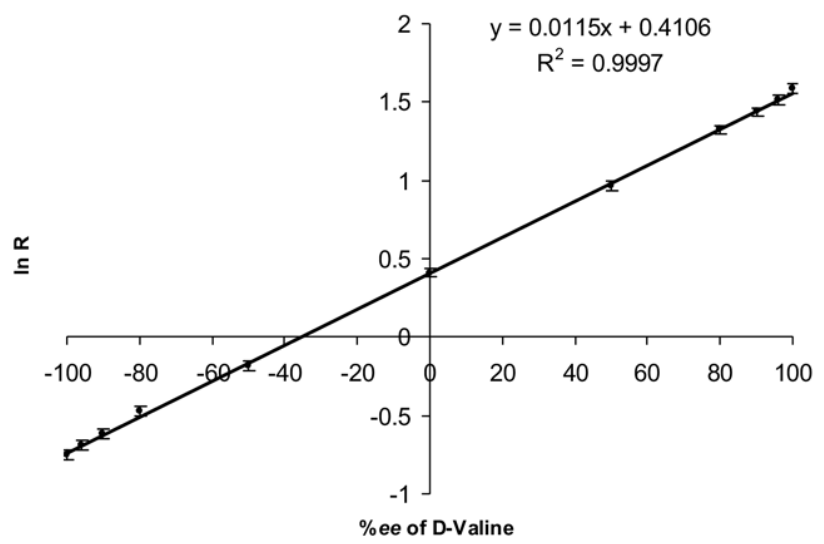

Figure 5. Calibration curve for chiral analysis of valine using $\mathrm{Cu}$ as the metal cation and L-3,5 diiodo-L-tyrosine as the chiral reference based on the triplicate measurements. Value corresponding to each point is an average of triplicate measurements made on different days. The error bars in the figure represent the standard deviations from the three triplicate measurements.
Table 4. Enantiomeric excess measurement of D-Valine using 3,5-diiodo-L-tyrosine as reference and $\mathrm{Cu}$ as central metal ion

\begin{tabular}{lrcc}
\hline Sample & Actual & Experimental $^{\mathrm{a}}$ & Relative error (\%) $^{-100}$ \\
\hline \hline 1 & -100.29 & 0.71 \\
2 & -98 & -97.72 & 0.28 \\
3 & -96 & -96.92 & 0.96 \\
4 & -90 & -91.44 & 1.6 \\
5 & 90 & 88.79 & 1.34 \\
6 & 100 & 100.8 & 0.8 \\
\hline
\end{tabular}

avalues shown are average of two separate measurements done at separate occasion.

meric excess for the studied amino acids in the range $2 \%$ to $100 \%$ ee with relative errors $0.28 \%$ to $1.6 \%$.

\section{Conclusions}

Herein we demonstrate the use of L-tyrosine and iodinated L-tyrosines (3-iodo-L-tyrosine or 3,5-diiodo-L-tyrosine) as chiral references for the discrimination of enantiomeric aliphatic, aromatic, and acidic amino acids. Chiral discrimination is achieved by measuring the product ion ratio of the two fragment ions formed by the dissociation of trimeric complex $\left[\mathrm{M}^{\mathrm{II}}(\mathrm{ref})_{2}(\mathrm{~A})-\mathrm{H}\right]^{+}$ion, where $\mathrm{M}=\mathrm{Ni}$ and $\mathrm{Cu}$, ref $=$ reference ligand, and $\mathrm{A}=\mathrm{D}$ or L-analyte. We measured $R_{\text {chiral }}$ values using the kinetic method to investigate the chiral discrimination and selectivity of iodinated L-tyrosines. Better $R_{\text {chiral }}$ values are obtained when $\mathrm{Cu}(\mathrm{II})$ is used as the central metal atom than $\mathrm{Ni}$ (II). Chiral discrimination ability increases with the number of iodine atoms in case of aliphatic and aromatic amino acids. Thus, the chiral selectivity can be improved to a greater extent by introducing the substituent on the reference itself. The 3,5-diiodo-L-tyrosine shows the highest chiral selectivity for all the aliphatic and aromatic amino acids. The data suggest the involvement of iodine atoms in the steric interaction leading to destabilization of the complex involving the L-analyte more compared with the D-analyte. In addition to the steric effect, $\pi-\pi$ stacking interaction (phenyl group of the reference and the carbonyl group of the analyte), $\pi$ - $d$ interaction (phenyl ring of the reference and metal atom), and interaction between iodine atoms and metal atoms may contribute to the chiral discrimination. The theoretically calculated results are in good agreement with the experimental data. Further theoretical and experimental investigations are in progress to explore the effect of nature and position of substituent on the aromatic ring for the chiral discrimination ability of the references. The application of the present method in the measurement of enantiomeric excess is also demonstrated; for the systems chosen, the ee values could be measured down to $2 \%$.

\section{Acknowledgments}

The authors thank Dr. J.S. Yadav, director of the Indian Institute of Chemical Technology, for the facilities and encouragement. SKD, CLD, and GKC thank the Council of Scientific and Industrial Research, New Delhi for the awards research fellowship. 


\section{References}

1. Nakanishi, K.; Berova, N.; Woody, R. V. In: Circular Dichroism: Principles and Applications; VCH Publishers: New York 1994, p. 39.

2. Gubitz, G.; Schmid, M. G. Chiral Separation Principles in Capillary Electrophoresis. J. Chromatogr. A 1997, 792, 179-225.

3. Mo, H. P.; Pochapsky, T. C. Intermolecular Interactions Characterized by Nuclear Overhauser Effects. Prog. Nucl. Magn. Reson. Spectrosc. 1997, 30, 1-38.

4. Pirkle, W. H.; Pochapsky, T. C. Considerations of Chiral Recognition Relevant to the Liquid Chromatography Separation of Enantiomers. Chem. Rev. 1989, 89, 327-338.

5. Maier, N. M.; Franco, P.; Lindner, W. Separation of Enantiomer: Needs, Challenges, and Perspectives. I. Chromatogr. A 2001, 906, 3-33.

6. Sawada, M. Chiral Recognition Detected by Fast Atom Bombardment Mass Spectrometry. Mass Spectrom. Rev. 1997, 16, 73-90.

7. Speranza, M. Enantioselectivity in Gas-Phase Ion-Molecule Reactions. Int. J. Mass Spectrom. 2004, 232, 277-317.

8. Krishna, P.; Prabhakar, S.; Manoharan, M.; Jemmis, E. D.; Vairamani, M. Chiral Recognition and the Determination of Optical Purity of Some Amino Acids Ester Salts Using Monosaccharides as Chiral Selectors Under Liquid Secondary Ion Mass Spectral Conditions. Chem. Commun. 1999, 1215-1216.

9. Krishna, P.; Prabhakar, S.; Vairamani, M. Chiral Recognition and Determination of Optical Purity of $\alpha$-Phenylethylamine Using Monosaccharide as a Chiral Selector Under Liquid Secondary Ion Mass Spectral Conditions Eur. J. Mass Spectrom. 1999, 5, 485-488.

10. Cong, X.; Czerwieniec, G., McJimpsey, E.; Ahn, S.; Troy, F. A.; Lebrilla C. B. Structural Relationships in Small Molecule Interactions Governing Gas-Phase Enantioselectivity and Zwitterionic Formation. J. Am. Soc. Mass Spectrom. 2006, 17, 442-452.

11. Ahn, S.; Ramirez, J.; Grigorean, G.; Lebrilla, C. B. Chiral Recognition in Gas-Phase Cyclodextrin: Amino Acid Complexes-Is the Three Point Interaction Still Valid in the Gas Phase? J. Am. Soc. Mass Spectrom. 2001, 12, 278-287

12. Ramirez, J.; Ahn, S.; Grigorean, G.; Lebrilla, C. B. Evidence for the Formation of Gas-Phase Inclusion Complexes with Cyclodextrins and Amino Acids. J. Am. Chem. Soc. 2000, 122, 6884-6890.

13. Bagheri, H.; Chen, H.; Cooks, R. G. Chiral Recognition by Proton Transfer Reactions with Optically Active Amines and Alcohols. Chem. Commun. 2004, 2740-2741.

14. Dearden, D. V.; Dejsupa, C. Liang, Y. J · Bradshaw, J. S. Izatt, R. M Intrinsic Contributions to Chiral Recognition: Discrimination Between Enantiomeric Amines by Dimethyldiketopyridino-18-Crown-6 in the Gas Phase. J. Am. Chem. Soc. 1997, 119, 353-359.

15. Filippi, A.; Gasparrini, F.; Pierini, M.; Speranza, M.; Villani, C. Exceptional Gas-Phase Enantioselectivity of Chiral Tetramide Macrocycles. J. Am. Chem. Soc. 2005, 127, 11912-11913.

16. Botta, B.; Botta, M.; Filippi, A.; Tafi, A.; Monache, G. D.; Speranza, M. Enantioselective Guest Exchange in a Chiral Resorcin(4)Arene Cavity. J. Am. Chem. Soc. 2002, 124, 7658-7659.

17. Schug, K. A.; Lindner, W. Stereoselective Discrimination and Quantification of Arginine and N-Blocked Arginine Enantiomers by Formation and Dissociation of Calcium-Mediated Diastereomeric Trimer Complexes with a Chiral Reference Compound Using Electrospray Ionization-Ion Trap Tandem Mass Spectrometry. J. Am. Soc. Mass Spectrom. 2005, 16, 825-834.

18. Yao, Z.-P.; Wan, T. S. M.; Kwong, K.-P.; Che, C. T. Chiral Analysis by Electrospray Ionization Mass Spectrometry/Mass Spectrometry. Chiral Recognition of 19 Common Amino Acids. Anal. Chem. 2000, 72, 5383-5393.

19. Ravi Kumar, M.; Prabhakar, S.; Vairamani, M. Chiral Discrimination of $\alpha$-Amino Acids by the DNA Triplet GCA. Chem. Commun. 2007, 392-394.

20. Tao, W. A.; Zhang, D.; Nikolaev, E. N.; Cooks, R. G. Copper(II)-Assisted Enantiomeric Analysis of D, L-Amino Acids Using the Kinetic Method: Chiral Recognition and Quantification in the Gas Phase. J. Am. Chem. Soc. 2000, 122, 10598-10609.

21. Zhang, D.; Tao, W. A.; Cooks, R. G. Chiral Resolution of D- and L-Amino Acids by Tandem Mass Spectrometry of Ni(II)-Bound Trimeric Complexes. Int. J. Mass Spectrom. 2001, 204, 159.

22. Nagaveni, V.; Prabhakar, S.; Vairamani, M. Differentiation of Underivatized Diastereomeric Hexosamine Monosaccharides and Their Quantification in a Mixture Using the Kinetic Method Under Electrospray Ionization Conditions. Anal. Chem. 2004, 76, 3505-3509.

23. Tao, W. A.; Wu, L.; Cooks, R. G. Rapid Enantiomeric Determination of $\alpha$-Hydroxy Acids by Electrospray Ionization Tandem Mass Spectrometry. Chem. Commun. 2000, 2023-2024.
24. Wu, L.; Clark, R. L.; Cooks, R. G. Chiral Quantification of D-, L-, and meso-Tartaric Acid Mixtures Using a Mass Spectrometric Kinetic Method. Chem. Commun. 2003, 136-137.

25. Wu, L.; Tao, W. A.; Cooks, R. G. Ligand and Metal-Ion Effects in Metal Ion Clusters Used for Chiral Analysis of $\alpha$-Hydroxy Acids by the Kinetic Method. Anal. Bioanal. Chem. 2002, 373, 618-627.

26. Augusti, D. V.; Carazza, F.; Augusti, R.; Tao, A.; Cooks, R. G. Quantitative Chiral Analysis of Sugars by Electrospray Ionization Tandem Mass Spectrometry Using Modified Amino Acids as Chiral Reference Compounds. Anal. Chem. 2002, 74, 3458-3462.

27. Tao, W. A.; Cooks, R. G. Parallel Reactions for Enantiomeric Quantification of Peptides by Mass Spectrometry. Angew. Chem. Int. Ed. 2001, 40, 757-760.

28. Chen, J.; Zhu, C.-J.; Chen, Y.; Zhao, Y.-F. Rapid Enantiomeric Quantification of the Bioactive Peptide Seryl-Histidine Methyl Ester by Electrospray Ionization Mass Spectrometry and the Kinetic Method. Rapid Commun. Mass Spectrom. 2002, 16, 1251-1253.

29. Augusti, D. V.; Augusti, R. Determination of the Enantiomeric Composition of Ibuprofen Solutions Via a Rapid and Sensitive Mass Spectrometry method. Tetrahedron Asym. 2005, 16, 1881-1885.

30. Tao, W. A.; Gozzo, F. G.; Cooks, R. G. Mass Spectrometric Quantitation of Chiral Drugs by the Kinetic Method. Anal. Chem. 2001, 73, 1692-1698.

31. Tao, W. A.; Wu; L. M.; Cooks, R. G.; Wang, F.; Begley, J. A.; Lampert, B. Rapid Enantiomeric Quantification of an Antiviral Nucleoside Agent (D, L-FMAU, 2 = -Fluoro-5-Methyl- $\beta$, D, L-Arabinofurano-Syluracil) by Mass Spectrometry. J. Med. Chem. 2001, 44, 3541-3544.

32. Wu, L.; Meurer, E. C.; Cooks, R. G. Chiral Morphing and Enantiomeric Quantification in Mixtures by Mass Spectrometry. Anal. Chem. 2004, 76, 663-671.

33. Wu, L.; Cooks, R. G. Chiral Analysis Using the Kinetic Method with Optimized Fixed Ligands: Applications to Some Antibiotics. Anal. Chem. 2003, 75, 678-684.

34. Cooks, R. G.; Wong, S. H. Kinetic Method of Making Thermochemical Determinations: Advances and Applications. Acc. Chem. Res. 1998, 31 379-386.

35. Eberhardt, N. L.; Apriletti, J. W.; Baxter, J. D. In Biochemical Actions of Hormones; Litwack, G., Ed. ; Academic Press: New York, 1980; Chap VII, p 311

36. Frisch, M. J.; Trucks, G. W.; Schlegel, H. B.; Scuseria, G. E.; Robb, M. A.; Cheeseman, J. R.; Montgomery, J. A., Jr.; Vreven, T.; Kudin K. N.; Burant, J. C.; Millam, J. M.; Iyengar, S. S.;Tomasi, J.; Barone, V.; Mennucci, B. Cossi, M. Scalmani, G.; Rega, N.; Petersson, G. A. Nakatsuji, H.; Hada, M.; Ehara, M.; Toyota, K.; Fukuda, R.; Hasegawa, J.; Ishida, M.; Nakajima, T.; Honda, Y.; Kitao, O.; Nakai, H.; Klene, M.; Li, X.; Knox, J. E.; Hratchian, H. P.; Cross, J. B.; Adamo, C.; Jaramillo, J.; Gomperts, R.; Stratmann, R. E.; Yazyev, O.; Austin, A. J.; ammi, R.; Pomelli, C.; Ochterski, J. W.; Ayala, P. Y.; Morokuma, K.; Voth, G. A.; lvador, P.; Dannenberg, J. J.; Zakrzewski, V. G.; Dapprich, S.; Daniels, A. D.; Strain, M. C.; Farkas, O.; Malick, D. K.; Rabuck, A. D.; Raghavachari, K.; Foresman, J. B.; Ortiz, J. V.; Cui, Q.; Baboul, A. G.; Clifford, S.; Cioslowski, J.; Stefanov, B. B.; Liu, G.; Liashenko, A.; Piskorz, P.;Komaromi, I.; Martin, R. L.; Fox, D. J.; Keith, T.; Al-Laham, M. A.; Peng, C. Y.; Nanayakkara, A.; hallacombe, M.; Gill, P. M. W.; Johnson, B.; Chen, W.; Wong, M. W.; Gonzalez, C.; Pople, J. A. Gaussian 03, revision B. 01; Gaussian, Inc.: Wallingford. CT, 2004

37. Seymour, J. L.; Turecek, F.; Malkov, A. V.; Kocovsky, P. Chiral Recognition in Solution and the Gas Phase. Experimental and Theoretical Studies of Aromatic D- and L-amino acid-Cu(II)-Chiragen Complexes. J. Mass Spectrom. 2004, 39, 1044-1052.

38. Odani, A.; Yamauchi, O. Structure-Stability Relationship in Ternary Copper(II) Complexes Involving Aromatic Amines and Tyrosine or Related Amino Acids. Intramolecular Aromatic Ring Stacking and Its Regulation Through Tyrosine Phosphorylation. J. Am. Chem. Soc. 1985, 107, 5938-5945

39. Yajima, T.; Takamido, R.; Shimazaki, Y.; Odani, A.; Nakabayashi, Y.; Yamauchi, O. $\pi-\pi$ Stacking Assisted Binding of Aromatic Amino Acids by Copper(II)-Aromatic Diimine Complexes. Effects of Ring Substituents on the Ternary Complex Stability. Dalton Trans. 2007, 299-307.

40. Zhang, F.; Odani, A.; Masuda, H.; Yamauchi, O. Structure and Stability of the Ternary Copper(II) Complexes with 3,5-Diiodo-L-Tyrosinate. Weak Interactions Involving Iodo Groups. Inorg. Chem. 1996, 35, 7148-7155.

41. Sugimori, T.; Masuda, H.; Ohata, N.; Koiwai, K.; Odani, A.; Yamauchi, O. Structural Dependence of Aromatic Ring and Related Weak Interactions in Ternary Amino Acid-Copper(II) Complexes and Its Biological Implication. Inorg. Chem. 1997, 36, 576-583.

42. Cambridge Structural Database; Cambridge Crystallographic Data Center (CCSD): Cambridge, England. 